\title{
Virtual models best live cells at predicting biology
}

A digital microbe confounds scientists' best predictions about its real-life counterpart's behavior. A virtual virus pinpoints new proteins that would elicit a strong immune response.

Those are just two examples of 'virtual cells', computer programs that mimic the complex ๖ biology of real organisms. Unlike pesky living cells, these cells multiply instantly, mimic any type of tissue and provide perfect reproducibility.

Although cell simulations have been available for years, they were designed by theoreticians out of touch with what biologists need. They required users to learn obscure mathematical techniques, and few showed biological relevance. The new generation of simulators is far easier for biologists to use.

"This isn't the old days of theoretical biology where the theoreticians never really interacted with people in the lab," says Les Loew, director of the Virtual Cell project at the University of Connecticut. "This is a tool for people in the lab to help them organize their experimental data and make predictions."

The number of scientists using Loew's system has quickly grown to nearly 16,000. Virtual Cell is freely accessible online and sports a graphical interface that is strikingly similar to the blocky cartoons biologists draw on whiteboards. By drawing them in the Virtual Cell interface instead, scientists can produce sophisticated simulations of entire cellular systems.

"[The program] automatically translates the reaction diagram into a mathematical description, and then it automatically produces simulations from those," says Loew. The simulations suggest experiments to test the model's underlying assumptions. Scientists can also share their models with others.

A similar program called Simmune helped create a virtual version of the common laboratory denizen Dictyostelium discoideum. The mold migrated toward virtual chemical attractants in a lifelike way, but displayed surprising molecular changes. The researchers hadn't looked for those changes before, but they confirmed that the model's unexpected predictions were correct.

"A lot of people who are not modelers think of modeling as curve-fitting, describing data that you already know, but that's not our goal," says Ronald Germain, senior author on the work (PLoS Comput. Biol. 2, e82; 2006). "We predicted new biology which we confirmed by experiment."

Using another program, scientists at the California-based La Jolla Institute for Allergy and Immunology created algorithms to predict the immune response against vaccinia virus, the basis of the smallpox vaccine. With the virtual immune system, the researchers predicted which structures, or epitopes, on the virus would bind most tightly to a cell surface protein that triggers antiviral immune responses. The predictions proved remarkably accurate, identifying several previously unknown viral epitopes (Nat. Biotechnol. 24, 817-819; 2006).

"I think this can narrow down the number of [vaccine] candidates that one wants to consider," says senior investigator Alessandro Sette. Simulation could also help predict a vaccine's effectiveness without exposing people to the virus, an important concern for smallpox and other potential biological weapons.

The resurging interest in virtual cells is driven in part by an improvement in user friendliness, but biologists are also adopting more technical approaches. For example, Harvard University scientists have developed a new computer programming language for cell modeling.

As virtual cells evolve, testing their predictions will still mean confronting the challenges of live cells. "We've gone a long way in building models and making people excited," says Jermey Gunawardena, a systems biology professor at Harvard, "but it's going to require some real breakthroughs at the level of single cell technology in order to really reap the benefits."

Alan Dove, New York

India is struggling to contain a polio outbreak that's threatening to undermine global efforts to eradicate the disease.

As of 17 October, India has 383 cases of polio, compared with 66 in all of 2005. More than $90 \%$ of this year's toll is in one district of the most populous state, Uttar Pradesh.

"Unless you clear this area, no other place in India is safe," says Shobhan Sarkar, assistant commissioner in charge of immunization in India's Ministry of Health and Family Welfare.

The Uttar Pradesh strain has also made its way into Nepal, Bangladesh, Angola, Namibia and the Democratic Republic of the Congo. "The risk of exportation of the virus from India into other countries remains high," says Margaret Thorley, public health advisor at the polio eradication branch of the US Centers for Disease Control and Prevention.

Many of these countries had been polio free for years before this strain created a problem. India, Pakistan, Afghanistan and Nigeria are the only four reservoirs of the wild poliovirus.

Experts have traced the spurt in India's

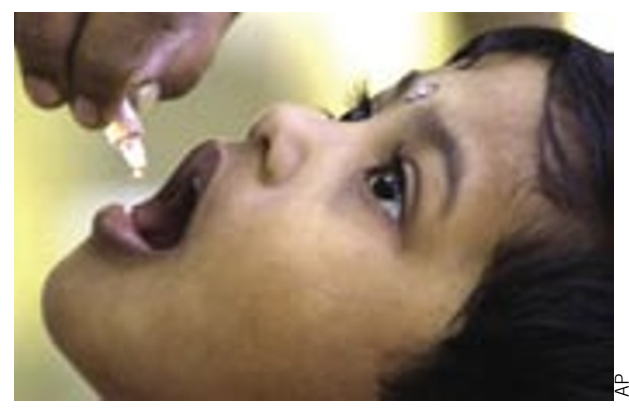

Missed shots: Vaccination campaigns missed $12 \%$ of children in the worst-affected district of India.

polio cases to children in Uttar Pradesh missed during immunization campaigns in late 2005 and early 2006. The state is saddled with poor infrastructure, inaccessible roads and inadequate water supply.

In Moradabad district, the proportion of houses with missed children rose from $8 \%$ in January 2005 to $12 \%$ in January 2006. That seemingly small difference adds up to a lot of people in Uttar Pradesh, where more than 500,000 children are born each month.
The state's health minister initially alleged that the outbreak was a result of substandard vaccines. But the World Health Organization has dismissed those charges.

The outbreak has renewed a long-standing debate over India's reliance on the oral polio vaccine (OPV). Made from a weakened virus, the oral vaccine is cheaper than an injectable vaccine developed from a killed virus.

"OPV is not as effective in India as in developed countries," says T. Jacob John, a member of India's advisory group on polio eradication The difference, he says, might be a result of microbes in the gut of Indian children and frequent diarrhea that makes children expel some of the vaccine.

But others disagree. "Every country before has been able to get rid of polio with OPV," notes David Heymann, the WHO's executive director of communicable diseases.

OPV is best suited for outbreaks, adds Thorley, because it doesn't depend on clean syringes, trained medical personnel or waste management.

T.V.Padma, New Delhi 